\title{
TRANSFORMAÇÕES NA CONVIVÊNCIA DE ADOLESCENTES JUNTO AO LABORTÓRIO DE INFORMÁTICA EM UMA ESCOLA PÚBLICA
}

*Patricia Ramos

\section{**Luciane Magalhães Corte Real}

RESUMO - O presente relato apresenta um estudo de caso das transformações na convivência de dois adolescentes junto ao Laboratório de Informática de uma escola da Rede Municipal de Ensino de Porto Alegre-RS, durante quatro meses, com freqüência de duas vezes por semana. Caracteriza-se por uma pesquisa intervenção, onde se utilizou a metodologia de Projetos de Aprendizagem. As observações foram registradas em diários de campo. Concluímos que, quando houve um encontro no emocionar dos alunos com o aprender, um espaço de convivência agradável estabeleceu-se, gerando aprendizado, tanto do conteúdo estudado, como das relações interpessoais. Observou-se que a tecnologia possibilitou, neste sentido, uma interação positiva entre os alunos, não se constituindo apenas em um recurso, mas em uma porta que se abriu para um novo aprender.

Palavras Chaves: informática na educação, projetos de aprendizagem, transformações na convivência.

\begin{abstract}
This a case study of two teenagers working together at a computer laboratory on a school in Porto Alegre city, Rio Grande do Sul state, for a period of four months, two times a week. This study is an intervention research based on learning projects methods. Field diaries were used to register the observations. The conclusion is that, when their feelings meet the learning process, in the Maturana point of view, a pleasant relationship is established, promoting learning in contents and interpersonal relationships. Technology used allowed a positive interaction between students, not being only a resource, but a door to a new learning process.
\end{abstract}

Key Words: learning projects, Technology in education, transformations continuously.

\section{Aprendizagem e Informática}

O uso da informática como potencializadora da aprendizagem tem sido de grande interesse nos últimos tempos. Através da informática, muitos conceitos difundidos, apenas em sala de aula, podem abranger e conquistar um novo espaço/tempo. Segundo FAGUNDES, et al. (1999) a chegada da tecnologia à escola trouxe possibilidades de algumas mudanças presentes nos sonhos dos educadores, como uma maior interdisciplinaridade. Entretanto, devemos considerar como a informática está sendo introduzida na escola, se apenas como reprodução de uma proposta pedagógica baseada no behaviorismo, onde os alunos vão somente copiar textos dados pelos professores, ou se é fundamentada em uma proposta ativa, de construção, de invenção. O presente relato trata de uma das possíveis leituras dos dados da tese Aprendizagens Amorosas na Interface Escola - Projetos de Aprendizagem -

\footnotetext{
Estudante de graduação em Psicologia/UFRGS. Bolsista SEAD, edital Objetos de Aprendizagem 05. patyarg@hotmail.com

** Profa. Faculdade de Educação UFRGS. Mestre em Psicologia do Desenvolvimento UFRGS. Doutoranda no Programa de Pós-graduação em Informática na Educação/UFRGS. lucreal@orion.ufrgs.br 
Tecnologias Digitais de autoria de Luciane M. Corte Real junto ao Programa de Pósgraduação em Informática na Educação/UFRGS e pretende mostrar como a informática, em uma proposta construtivista, pode interferir de maneira positiva na convivência de alunos em uma Escola Municipal de Porto Alegre.

Foi utilizada a metodologia de Projetos de Aprendizagem (PA), como descrita por FAGUNDES et al. (1999). As autoras citadas diferenciam duas possíveis propostas no trabalho com a informática, os Projetos de Ensino e os Projetos de Aprendizagem.

Nos Projetos de Ensino o tema a ser estudado parte do professor e da coordenação pedagógica da escola; segue os conteúdos programáticos das matérias que constam no currículo escolar, oportunizando pouca interdisciplinariedade. O professor é o agente do processo (o responsável por ele) e o aluno deve ser receptivo à proposta de seus mestres. O paradigma presente é o da transmissão do conhecimento.

Nos PAs, o tema a ser estudado é levantado pelos alunos, de forma individual e em grupos, juntamente com os professores e a coordenação pedagógica. Os assuntos escolhidos satisfazem a curiosidade, os desejos, as vontades e as necessidades dos aprendizes. As regras e diretrizes são elaboradas pelo grupo de alunos e professores. Ao professor cabe o papel de problematizador e de desafiador. O aluno é o agente do processo. O paradigma presente é o da construção do conhecimento.

Observamos na proposta de Projetos de Aprendizagem, uma nova e significativa organização do papel de professores e alunos. O aprendiz é desafiado a questionar e argumentar. Com isso, se perturba e necessita refletir para expressar suas dúvidas. É explorada sua capacidade de formular e equacionar problemas, pois lhe é permitido propor questões que tenham significação a ele. Essa significação emerge de sua história de vida, de seus interesses, de seus valores, de suas necessidades e de suas condições pessoais. Quem consegue formular, com clareza, um problema começa a aprender a definir as direções de sua atividade. Os Projetos de Aprendizagem trabalham, a partir da autoria, no sentido de se referir à formulação de questões pelo autor do projeto, pelo sujeito que vai construir o conhecimento.

\section{Transformações na convivência: aprender para Humberto Maturana}

Segundo MATURANA (1993) a história individual percorre interações recorrentes, mas a reação de cada um depende de como está organizada a sua estrutura. Essa estrutura, que rege as reações, é a história das vivências e experiências. As estruturas passam por modificações com o passar do tempo, pois o sujeito esta exposto a diferentes circunstâncias e meios que o transformam como ser vivo. É através dessas interações que acontece a transformação na convivência do ser vivo.

Educar para MATURANA (1993), é configurar um espaço de convivência desejável que possibilite um fluir no conviver. Quando se consegue aceitação do outro para participar desse espaço o educar flui de maneira que não se torna um pesado fardo. A tarefa do educador é permitir que esse espaço seja configurado e abra o convite para a aceitação de uma convivência no âmbito do saber, assim haverá o encontro na emoção com o outro. MATURANA (1993) afirma que a transformação na convivência se dá quando existe a aceitação do outro na relação como legítimo outro, com suas diferenças e desigualdades. Quando há ações construtivas, uma configuração desejável fluirá dentro do espaço de convivência. Configurar esse espaço dentro do ambiente de informática faz com que os alunos tenham um encontro no emocionar do outro, dando a possibilidade de modificar a estrutura, transformando-se na convivência. Aceitando os projetos, as idéias, as sugestões, as ajudas, a criança e o professor terão um encontro no campo do emocionar, possibilitando a sociabilidade e afetividade (MATURANA, 1993). 
Quando eu ofereço a mão e uma criança aceita, eu também estou aceitando a mão da criança (MATURANA, 1993).

Ajudar os alunos no processo de conhecimento é o dever de toda a escola, como também proporcionar a possibilidade de aprender sobre as emoções. A informática insere-se num campo de novas tecnologias que pode oferecer ao aluno riquezas para o aprendizado em uma maior totalidade, pois pode-se utilizar outros recursos além da sala de aula convencional, como o bate-papo, o fórum, as pesquisas na internet, etc.

A Informática e a Telemática podem ajudar a enriquecer os ambientes de aprendizagem, podem ampliar os espaços das salas de aula, podem vencer as barreiras do tempo, podem servir como "próteses" cognitivas, podem ajudar a ampliar os processos socioafetivos e a conscientização, podem ajudar a atender os aprendizes como verdadeiros sujeitos de sua aprendizagem, podem assegurar a intercomunicação coletiva, podem ajudar a criar comunidades de aprendizagem e desenvolvimento. (FAGUNDES et al. , 1999, p. 14)

Com este intuito vamos abordar a análise de um caso que nos proporciona uma discussão sobre como a informática pode auxiliar positivamente nas relações socioafetivas de alunos.

\section{Experiência com Informática na Escola: Um estudo de caso}

A experiência foi realizada em uma das escolas da Rede Municipal de Educação de Porto Alegre/RS. O modelo dos currículos da rede vem de reformas propostas desde 1994, chamado "Ciclos de Formação". De acordo com essa proposta pedagógica, o objetivo é baseado na organização com eixos temáticos, respeitando critérios de idade e conhecimento. Os alunos não pertencem a séries de classificação, mas se ajustam aos ciclos que tenham o perfil de sua idade-conhecimento. São divididos em três Ciclos: Ciclo I corresponde à infância, o Ciclo II corresponde à pré-adolescência e, o III, à adolescência. A organização dos Ciclos é feita pelas fases da vida, ou seja, pelo tempo de existência do indivíduo e não necessariamente pela divisão do tempo em anos.

A progressão dos alunos ocorre através das avaliações realizadas conforme o desempenho nos eixos temáticos, que contemplam as disciplinas do currículo da LDB (Lei de Diretrizes e Bases). Os alunos que não se adaptam à idade/ciclo permanecem nas "Turmas de Progressão" ou nos "Laboratórios de Aprendizagem", que têm por objetivos uma futura adequação de estudantes às turmas de ciclo e trabalho com as dificuldades atuais. A escola Municipal, onde a experiência ocorreu, conta com um laboratório de informática conectado a rede de Internet e inserido nos projetos de formação por ciclos.

As seguintes reflexões partem da experiência de trabalho dentro do projeto de pesquisa de doutorado citado, que objetivava uma experiência de transformações na convivência com alunos, utilizando a metodologia de Projetos de Aprendizagem e Informática. Os alunos observados pertenciam a duas turmas do ciclo B30, composto por alunos com idade entre 11 e 12 anos. A sala de informática continha 15 máquinas, cada uma com duas cadeiras. Os alunos foram entrevistados e observados antes do começo das atividades. Por pertencer a uma comunidade carente, 99\% não dispunham de computador. Foram eles interrogados sobre modos de aprendizado, e muitos se referiram que o local onde se aprende é na escola. A maioria demonstrava interesse em ter aulas na sala de informática e associavam isso com joguinhos no computador.

No primeiro dia de atividades, os alunos foram desafiados a participar em grupo 
de trabalho, pois a turma era composta por 30 alunos e haviam apenas 12 computadores funcionando. Demonstrando euforia, os alunos se dirigiam para os computadores disponíveis. Entretanto alguns ficavam paralisados, pois não tinham colegas com afinidade para dividir o computador com os já sentados. A aluna K., ficou emburrada, pois não tinha colega para dividir o computador. O menino $\mathrm{R}$. estava só, e a professora incentivou $\mathrm{K}$. a sentar com o colega R. para que pudessem trabalhar juntos. A aluna K. não gostou da idéia e ficou muito brava, pois referia não se sentir a vontade com 'guris'.

O primeiro desafio oferecido aos alunos foi a construção de uma página pessoal. Ela deveria conter os dados pessoais e informações sobre o que gosta de fazer, comer, brincar, entre outros assuntos de suas preferências. Os alunos, de maneira geral, sentiram muita dificuldade em escrever sobre eles próprios. Uma grande limitação foi a falta de conhecimento tecnológico por partes deles. Muitos nunca tinham trabalhado na produção de texto no computador, se atrapalhavam com o uso do mouse, do teclado e com as funções do ambiente virtual. Esse primeiro momento foi também de ajuste para as duplas que dividiam os computadores. Começou nesse período um momento de negociação: quem escreve primeiro, quem escreve depois, opiniões sobre cor de letra, fundo de tela, etc. $\mathrm{O}$ interessante foi que os participantes começam a se interessar pela página do colega, o que o outro escreveu sobre si mesmo. Assim começa uma descoberta sobre seus colegas. Quando as páginas pessoais foram concluídas, os alunos foram desafiados a escolher um assunto para pesquisar.

A elaboração da pesquisa seguiu a metodologia de Projetos de Aprendizagem como descritos por FAGUNDES et al. (1999), onde os alunos escreveram primeiramente suas dúvidas temporárias e suas certezas provisórias acerca do tema escolhido pelo grupo. Essa atividade, para que fosse realizada, pressupunha um acordo entre as duplas ou trios na escolha do assunto, e esse processo de escolha gerou dificuldades em alguns grupos. A dupla de alunos K. e R., não conseguiu entrar em um acordo - uma menina e um menino que tinham gostos muito diferentes e que antes nunca haviam trabalhado como colegas do sexo oposto. A aluna K., mostrava o desejo de pesquisar sobre moda, e o aluno R. não desejava este assunto. Após muita discussão os alunos conseguiram chegar em um consenso e optaram por pesquisar sobre planetas. $\mathrm{Na}$ lista das certezas, K. e R. Expuseram o que conheciam sobre os planetas do Sistema Solar, e nas dúvidas mencionaram querer saber se existem outros planetas no Sistema Solar. Durante esse processo os alunos mostraram boa aceitação das idéias de um e do outro. Para colocar suas idéias na página da pesquisa cada um ia digitando um pouco. Observamos que em algumas semanas de convivência, os alunos começam a estreitar laços de afinidades.

Após alguns encontros, a aluna K. começou a guardar o lugar para o colega R.. Eles já dominavam melhor a informática, a navegação na Internet, trabalhavam com o buscador Google podendo escrever mais sobre curiosidades do Sistema Solar. R. mostrou grande interesse em auxiliar os colegas de outros grupos com dificuldades em gravar os textos e inserir imagens, pois já tinha conhecimento de como eram esses passos. K. passou a se preocupar com a estética do texto, com as cores utilizadas. Na busca por sites, os alunos encontraram com uma página com muitas figuras de planetas, e começam a inserir as imagens na pesquisa. Visitam o site da NASA, mas não se deram conta disso. Os dois ficaram atentos a cada figura, cada imagem contida no site, apesar do conteúdo ser em inglês. Com essa descoberta, K. e R. chamaram os colegas para que vissem o novo achado. $O$ espaço se tornou pequeno para os colegas visualizarem as imagens dos planetas.

Os alunos começaram a estreitar seus laços solidários. As dificuldades no lidar com o computador, não foram mais respondidas pelos estagiários ou pelo professor. Eles mesmos se ajudavam e se envolviam nas pesquisas uns dos outros. Após o término 
das pesquisas os alunos foram convidados a realizar uma pré-apresentação de seu trabalho. Nesse momento as duplas começaram a falar sobre o que estavam pesquisando, e os colegas passaram a opinar sobre o que se deveria melhorar ou acrescentar. Muitas duplas se deram conta que deveriam colocar mais informações ou mais imagens. As pesquisas variaram de Funk até Tornados e Ciclones. K. e R. sentaram-se juntos, e demonstraram ter iniciado uma relação afetiva com uma aceitação um do outro no trabalho, conseguindo interagir a partir de suas diferenças. As discussões, no grande grupo, foram sobre o que fazer para melhorar a pesquisa. Queriam saber se podiam escanear imagens para melhorar o trabalho e demonstraram preocupação por terminar a pesquisa com bons resultados. No final do segundo mês, os alunos são convidados a participar de um bate-papo acompanhados dos professores da turma juntamente com a pesquisadora. K. e R. sentaram separados, e trocaram elogios. $\mathrm{K}$. disse que acha R. muito querido, que gostava de pesquisar com ele. R. diz que K. é muito legal.

\section{Conclusões preliminares}

Concordamos com MATURANA (1993) que é nesse encontro com o emocionar do outro que se torna possível um espaço relacional de convivência aceitável. Com essa configuração, o aprendizado é favorecido para todos envolvidos no processo, professores e alunos. Através desse breve relato podemos concluir que a produção do encontro no emocionar se estabeleceu graças às interações ocorrida no sala de informática mediada por uma proposta construtivista. Também se pode observar que, apesar da pouca familiarização com o teclado e/ou mouse, os alunos mostraram muita disposição quando desafiados. A curiosidade impulsionou o conhecimento tecnológico, o desenvolvimento da escrita, da pesquisa, do aprendizado em geral. As relações solidárias estabeleceram um espaço colaborativo, onde os alunos sentiam-se estimulados a ajudar os colegas com dificuldades. No primeiro momento da observação os alunos entravam eufóricos e competiam individualmente para trabalharem com os melhores computadores. Com o passar do tempo, a interação com os colegas e equipe de trabalho proporcionaram um clima de solidariedade e cooperação inclusive na escolha do grupo e dos computadores.

\section{Referências}

DA SILVA, SIONY. A Evolução Tecnológica e a Educação a Distância. Revista 
Sinergia, Vol 2, 2001. Disnponível em: http://www.cefetsp.br/edu/sinergia/7p9c.html . Acesso em: 01.jul.2006

FAGUNDES, LEA.; SATO, LUCIANE. ; MAÇADA, DEBORA Aprendizes do Futuro: as inovações começaram. 1999. Disponível em <www.inf.ufsc.br/ edla/mec/livro03.pdf. $>$ Acesso em: 01. jul. 2006.

MATURANA, HUMBERTO. Uma nova concepção de aprendizagem. Dois Pontos, v. 2, n. 15, 1993.

CORTE REAL, LUCIANE. Aprendizagens Amorosas na interface Escola - Projetos de Aprendizagem - Tecnologias Digitais. Projeto de Tese, Programa de Pósgraduação em Informática na Educação/UFRGS, 2006. 